\title{
Constructivist-based Instructional Design of Workshop and Discovery
}

\author{
Yanxi Zhu \\ Qingdao Harbor Vocational and Technical College, Qingdao, Shandong Province, 266404, China \\ zhuyanxi@sina.com
}

\begin{abstract}
Based on the analysis of workshops teaching mode, this article integrated the constructivist concept into workshops and elaborated the four elements which should be underlined in conduction of constructivism workshop. Three patterns of constructivist instructional design workshops were developed and the respective roles of teachers and students playing in the workshop also were discussed and cleared in this paper.
\end{abstract}

Index Terms - Constructivist Workshop Instructional design Discovery Learning mode

\section{Introduction}

Effective teaching begins with effective planning. Instructional design provides asystematic process for planning instructional events based on a systematic process of applying principles of learning and instruction to plans for instructional systems[1-2]. Constructivist instructional design principles involve embedding learning in complex real world problems, providing a rich and flexible learning environment with goals and objectives set by the learner, emphasizing continuous assessment that is embedded in the instruction, facilitating multiple perspectives and social negotiation as integral parts of learning, and encouraging ownership in learning by actively engaging in the process of knowledge construction. Such prescriptive instructional guidelines, the constructivist approach, are more frequently being used by instructional designers. Constructivism holds that knowledge is not taught by teachers, but obtained by learner through the construction of meaning. The knowledge is accepted with the aid of the necessary learning materials and the help from other people such as teachers, students, other learning partners with in certain contexts [1]. The learning process is one in which the learner examines prior their knowledge and experience in a certain situation and rebuild their own knowledge and understanding. Workshops originally appeared in the field of education and psychology since the 1960s when Lawrence Halprin first introduced the concept of the workshop to the city plan and then gradually developed to become an approach of joint participation for groups through communication and collaboration, experience sharing and other ways of problem solve. At present, workshops, as an important teaching way, are widely used in instructional design to solve the problem in the form of a group by playing groups advantages through specific design.

According to the theory above, the teaching team can be divided into groups to build workshops and make the use of ideology of constructivist instructional design to enable students to take advantage of group to mutually stimulate each other and accomplish the knowledge reconstruction.

\section{Key Elements of Constructivist Learning Environment in Workshop}

The four key elements underlined in conduction of constructivism workshop are summarized as "situation", "cooperation", "conversation" and "construction of meaning", of which instructional design depends critically on ability of learners to reconstruct new knowledge system based on their existing learning experience [2]. To ensure the successful implementation of constructivist teaching mode, one should pay attention to the application of four elements in the workshop design process.

\section{A. Comprehensive Situation Design}

During the process of building learning environment in the workshop, it is very important construct to the knowledge system that is conducive to the students. This workshop design put forward higher requirements for teachers. First, the teacher not only is responsible for the teaching objectives of situation design, but also the factors that help students creat construct meaning. Thus, the constructivist teaching should try to simulate a real situation, fully enrich the relevant elements, and perform role-play if necessary to make everyone consensus on the scene by strict rules.

\section{B. Effective Teamwork}

Cooperation has always been throughout the learning process and plays an important role in students' data collection of questions analysis, experiences share, knowledge restructuring, as well as the overall significance of outcome evaluations. Therefore, to ensure the workshop positive and effective in a collaborative process, a leader is necessarily required in the initial operation of workshop. It is critical for leaders to clear their own roles in the situation. The leader who works much more obviously at the first stage is generally responsible to control of the development of group activities. When the conducting activity reaches a relatively mature stage or after the members of the workshop have certain knowledge and understanding of the teaching objectives, it needs to play down the role of leader until no leader existence at last. Leaders ultimately only become as common group member. The mature stage of effective collaboration is the group

\footnotetext{
* This work was supported by the Domestic Visiting Scholars' Project for Outstanding Young Teachers in Higher Education University of Shandong Province.
} 
without leader and in which members of the group can completely release their thinking, of which the group has successfully achieved effective teamwork [3].

\section{Deep Communication and Conversation}

Communication session is an important carrier for activities course throughout the workshop. In-depth communication is helpful to stimulate thinking and share experience between members of the group and to cohesion the wisdom. Thus also it is an important means to ensure the construction of meaning. In order to achieve deep conversation in the workshop, it need to set necessary rules to students for process promotion and real situation stimulation but should be careful not to cover up the performance tension of students. Teacher should control the reviews, comments, summary and praise of the group member performance so that to facilitate future growth and development of the team.

\section{Complete Construction of Meaning}

Because the learning process is highly divergent in the environment of workshop, construction of meaning is the ultimate goal of the whole learning process. In order to help the students deeply understand what they have learned and form a recognition knowledge system as well as ensure a relatively complete meaning of construction, teacher should pay special attention to the stage of summary and comments. The comment should be careful and give much consideration. Teachers have not only to ensure he workshop environment successfully work and the learning atmosphere is interfered by outside environment as little as possible, but also pay attention to the status of students' understanding of the knowledge to form a long-term effective storage in the brain. Only in this way, the students will have a relatively complete structural or cognitive system for what they have learned.

\section{Discovery on Several Patterns of Constructivist Workshops}

In the constructivist teaching workshops, effects teachers, students, teaching materials and media and other elements are completely different comparing with the traditional method. In this workshop, student can play not only the role of leader or participant during the whole learning process but also can be the active constructer of knowledge system. Teachers, as an normal participant, also play a potential role of guide, help, and facilitator in the workshop. Textbooks and the media just work as the tool used for the knowledge construction. The author of this article explored three different patterns of workshops to complete the constructivist teaching based on the constructivist teaching mode in combination with the practical experience applying teaching workshops from HKUST.

\section{A. Frame Pattern Workshop}

Frame pattern of the constructivist workshops mainly consists of the following aspects of the composition.

1) Framework Construction In accordance with prior knowledge to build a conceptual framework for students to clear his similar framework for understanding new knowledge and help teachers to achieve the final construct teaching objectives in the process of four elements of the implementation.

2) Situational Integration In general, teacher proposes an issue by introducing an example to students and put them into a thinking context. It allows students to participate in by free play and extensive discussion.

3) Independent Discover The focus of this session is to allow students to explore new knowledge independently. At the beginning of the discovery, students are first inspired and guided by the workshop leaders and then analyzed themselves. In the exploring process, the leader gives timely guild at a critical point to help students gradually rising up along conceptual framework.

4) Collaborative Learning It is a normal phenomenon that workshop team members are likely to break up some existing knowledge property and be in violation of the established rules and principles appearing many conflicting opinions after the start of the process of workshop consultation and discussion, but the question from the complex situation will become gradually clear and be consistent up by increases of leadership in the workshop. On the basis of result of collective thoughts, the more comprehensive, systematic and proper understanding and awareness of the current knowledge could be achieved ultimately and the teaching objectives of meaning construction can be completed. The leader cannot force but take care the thinking of students and thoroughly analyze the causes at the effect evaluation stage even though such a development cannot be achieved. The teacher should make comments and give recommendations in accordance with the actual situation.

5) Effect Evaluation and Comments Evaluation of the effectiveness of learning includes students' personal self- and peer evaluation among groups. The content of evaluation may include self-learning ability of group member, contribution to collaborative learning, effect of communication and collaboration, personal feelings in the learning process and whether completion the meaning construction of the knowledge and so on. Review and comment section is not required, but can be set according to the final workshop panelist developments. The review should be avoided on the comment of attributes of right and wrong.

\section{B. Anchor Pattern Workshop}

Anchor pattern of the constructivist workshops mainly consists of the following aspects of the composition.

1) Situations Creation Create the basically the same or similar learning situations with the realities through multimedia or the creation of other teaching resources.

2) Implementation of Anchor Choose a focus or the authentic event closely related to the central question as a central element of the discussion in the constructed situation. Select the "anchor" of event or problem, and then threw out a problem as the "anchor". The choice of the "anchor" is quite crucial in this session.

3) Self-exploration In the learning process of students' independent exploring, teachers should not tell students how to solve problems in face directly, but can deliberately guide students discuss toward an unexpected direction according to 
the thinking of students and then change the boot when the discussion direction occurred obstacle. The teacher should avoid always being a leader or authority and try to play an equal role as participant in the workshop since the leadership can make students' thinking limited.

4)Collaborative Learning Through discussion, communication and the exchange of different viewpoints and friction to enhance the "anchor" understanding of each student and complete rebuild process for knowledge.

5) Effect Evaluation and Comment The objective of the Anchor Pattern Workshop is to solve the problem, so the purpose of the evaluation of results should be very clear. Observation points can only focus on "anchor" and do not do much evaluation test. Review of this model is necessary since you have to process to summarize questions.

\section{Random Access Pattern Workshop}

Random access pattern of constructivist workshops mainly consists of the following aspects of the composition.

1) Situation Presents According to what was learnt, the situation presented should be related to the current learning objectives and content that should be designed fleshly as fully as possible.

2) Random Accesses According to the previous scenario, the members of the workshop are randomly selected to enter the discussion of different learning content but related. In this process, teachers as an ordinary member of the team should pay much more attention and make students fully self-learning to gradually learn autonomously.

3) Thinking Expedition The learning content involved in the workshops is generally diverse and complex due to the enter point of the learning content with a certain degree of randomness. Because of the wide range of the research, it requires teachers fully take care ability development of students and summary and records in the process of divergent thinking.

4) Collaborative Learning The discussion can be made around the different sides of the situation between groups of different workshop. In this process, different views of the group members will be examined in the negotiating environment, at meanwhile students can repeat thinking to make adjustment of his/her own viewpoint according to others [4-6].

5) Effect Evaluation and Comments This part may involve self-improvement, the contribution to group collaborative learning, and their own feelings in the learning process as well as whether the completion of the knowledge for construction of meaning.

Three modes of workshops above can be designed in the specific operation according to number of people in the class. The teacher should first train team leader who needs to prepare the course in advance so that to play potential leaders in the group in the easy way. The selection of people for leadership should keep secret. When the group is small, it can arrange groups to participate in situation one by one, with the other groups on the sidelines.

\section{Roles of Teachers and Students in the Constructivist Workshop}

Teachers of constructivist teaching workshops are no longer simply imparting and instilling knowledge to students, and students are not passive recipients of external stimuli and infused objects $[7,8]$.

\section{A. Requirement for Teacher in Constructivist Workshop}

1) Encourage and Motivation Guide students to generate interests in learning and encourage students to develop learning motivation and study habits.

2) Good Design Choose and design the situation according to the actual and participate in the workshop as group member and guide other members to discuss the old and new knowledge and make link between them as well as to guide students come into divergent thinking to help them construct the objective knowledge .

3) Appropriate Guidance Method Note the guidance methods and pay much attention to inspire and induce students to discover their own ability, to correct themselves and give supplement their incomplete understanding. Try not to pick out the trend of development and allow for a larger gap between the expectations and design results because even these results do not occur for now but will happen in the future and probably zoom doubly which also require teachers of strong ability to respond to high demands .

4) Objective Comments Evaluation and review for students' performance should be objective and proposed as in the form of suggestion to avoid indoctrination amendment.

\section{B. Requirements for students in constructivism workshop}

1) Comply with conventions and rules of the workshop conducive to present the real situations.

2) Make use of thinking of exploration and discovery to collect and analyse all of relevant information and data, and verify various assumptions rose on learning problems.

3) Brave to challenge the existing experience. Correct their existing experiences and perspectives through consultations in and discussions in workshops.

4) Emphasize teamwork. Consultation of group member is necessary even the internal fierce debate is inevitable, but the group is always a team in which member learn from each other and grow together.

\section{References}

[1] Black, J.B. McClintock, R.O., "An interpretation construction approach to constructivist design," In B. Wilson (Ed.), Constructivist learning environments, New Jersey, Educational Technology Publications, pp. 25-32, 1996.

[2] Jonassen, D.H., "Evaluating constructivist learning," In T.M. Duffy \& D.H. Jonassen, Constructivism and the technology of Instruction, New Jersey, Educational Technology Publications, pp. 137-148, 1992.

[3] Herrington, J., Oliver R., Reeves, T. C, "Patterns of engagement in authentic online learning environments," Australian Journal of Educational Technology, Vol.19, no.1, pp. 59-71, 2003.

[4] Herrington, J., Oliver, R., "An instructional design framework for authentic learning environments," Educational Technology Research and Development, Vol. 48, no.3, pp. 23-48, 2000.

[5] Lochhead, J., "Making sense of thinking," In Arthur L. Costa (Ed.), Developing Minds: A Resource Book for Teaching Thinking. pp. 413- 
416, 2000.

[6] Swartz, R., "Infusing critical and creative thinking into content instruction," In Arthur L. Costa (Ed.), Developing minds: A resource book for teaching thinking, pp. 266-274, 2000.

[7] M. M. Lombardi, "Authentic Learning for the 21st Century: An
Overview" Educouse Learning Initiative -advancing Learning through IT innovation, pp.1-12, May, 2007

[8] S. Gold, "A Constructivist Approach to Online Training for Online teachers," JALN, Vol. 5, no. 1, pp. 35-57, May, 2001 